\title{
ERRATUM
}

\section{Joint Moment and Mechanical Power Flow of the Lower Limb During Vertical Jump}

\author{
S. Fukashiro and P.V. Komi
}

Department of Biology of Physical Activity, University of Jyväskylä, Jyväskylä, Finland

Int. J. Sports Med. 8 (1987) 15-21 Supplement

The figure of Appendix 1 and the three equations should read as follows:

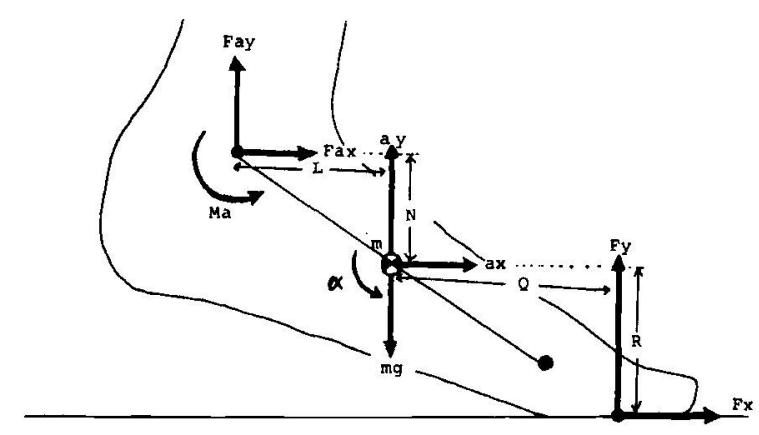

1. $F a x=\max -F x$

2. $F a y=m a y-F y+m g$

3. $\Sigma \mathrm{M}=\mathrm{I} \alpha$

$\mathrm{Ma}+(\mathrm{Fx} \cdot \mathrm{R})+(\mathrm{Fy} \cdot \mathrm{Q})-(\mathrm{Fay} \cdot \mathrm{L})-(\mathrm{Fax} \cdot \mathrm{N})=\mathrm{I} \alpha$

$\therefore \mathrm{Ma}=-(\mathrm{Fx} \cdot \mathrm{R})-(\mathrm{Fy} \cdot \mathrm{Q})+(\mathrm{Fay} \cdot \mathrm{L})+(\mathrm{Fax} \cdot \mathrm{N})+\mathrm{I} \alpha$

Fax, Fay $=$ joint reaction force

$\mathrm{Ma}=$ moment of the joint

$\mathrm{Fx}, \mathrm{Fy}=$ ground reaction force

ax, ay = acceleration of the center of segment

$\mathrm{m}=$ segment mass

$\mathrm{g}=$ gravity due to acceleration

$\mathrm{I}=$ inertia moment of the segment

$\alpha=$ angular acceleration of the segment

$\mathrm{L}, \mathrm{N}, \mathrm{Q}, \mathrm{R}=$ distance 